\title{
Role of Percutaneous Transcatheter Embolization of Gonadal Vein Using N-Butyl Cyanoacrylate in Treatment of Varicocele
}

Lobna Abdelmonem Habib, Nermeen Nasry Keriakos, Khaled Essam Basiouny

Radiology Department, Faculty of Medicine, Ain Shams University, Cairo, Egypt

Corresponding author: Khaled Essam Basiouny, Mobile: +201141682108, E-mail: khaledbasiouny19@gmail.com

\begin{abstract}
Background: Percutaneous embolization of the internal spermatic vein to treat varicoceles is a minimally invasive outpatient procedure that, when performed by experienced interventional radiologists, has high technical success rates, low recurrence rates, very low morbidity and minimal radiation. It has been demonstrated to be equal to surgical ligation in clinical results and as or more cost effective. Its minimally invasive nature allows it be well tolerated with shorter recovery times and less discomfort relative to surgery. When skilled and experienced vascular and interventional radiology services are available, embolization is an effective alternative to surgery and should be offered as such or as primary therapy for varicocele treatment.
\end{abstract}

Objective: The aim of this study is to discuss the role of N-buty cyanoacrylate for gonadal vein embolization in treatment varicocele causing testicular pain or infertility.

Methodology: this study was carried out in Radiology Department of Ain Shams University Hospitals.

This cross sectional descriptive study included 20 patients with varicocele presented by pain, infertility or recurrence after surgery and diagnosis was confirmed by ultrasound.

Result: varicocele embolization has significant role in improving scrotal pain and infertility.

Keywords: Varicocele, gonadal vein, butyl cyanoacrylate, primary infertility, percutaneous embolization

\section{INTRODUCTION}

Varicoceles, a dilation of veins within the pampiniform plexus, are present in $15 \%$ of the general male population. It is also one of the most frequent causes of male-factor infertility, with a prevalence of $30 \%-40 \%$ among men presenting for primary infertility evaluation and up to $85 \%$ in secondary infertility ${ }^{(\mathbf{1})}$.

Color Doppler ultrasound detects a varicocele either by measuring augmented scrotal vein size or by demonstrating blood refluxing through the pampiniform plexus during the Valsalva maneuver. The measurement of retrograde peak flow creates a possibility to detect further subclinical varicoceles $^{(2)}$.

The indications of non medical intervention for clinically significant varicocele include infertility or subfertility specially with impaired semen parameters, hypogonadism, scrotal pain, and testicular atrophy. Treatment options for varicocele can be divided into two major categories: (1) percutaneous occlusion, by intravenous injection of various materials to occlude the varicoceles and (2) surgical ligation or clipping of the varicoceles to prevent venous reflux ${ }^{(3)}$.

Surgical ligation and percutaneous embolization of the internal spermatic vein are the main therapeutic options for men with varicocele. By comparison with surgical ligation, percutaneous embolization is a cheaper and less invasive method, requiring only local anesthesia and allows visualization of the internal spermatic vein and possible collaterals ${ }^{(4)}$.

Percutaneous embolization of varicocele requires selective catheterization of the internal spermatic vein(s) followed by its occlusion with $\mathrm{N}$ butyl cyanoacrylate: lipidol mixture ${ }^{(5)}$.

Between 3-5 months after the procedure, patients attend another appointment. For patients referred because of testicular pain, complete absence of symptoms was considered as clinical success. Regarding patients treated for infertility, sperm analysis immediately before and at least 3 months after the procedure was performed. Sperm concentration, motility and morphology after the procedure were compared to those before the procedure. Values of 15 million sperm/mL, $40 \%$ of motile sperm and $4 \%$ of morphological normal forms were used for considering normalization and clinical success ${ }^{(6)}$.

\section{AIM OF WORK}

The aim of this study is to discuss the role of $\mathrm{N}$-buty cyanoacrylate for gonadal vein embolization in treatment varicocele causing testicular pain or infertility.

\section{PATIENTS AND METHODS}

Patients: During a period of 6 months duration from December 2017, twenty patients were enrolled in the study. All patients with varicocele, diagnosed by ultrasound and scrotal Doppler, 10 patients presented with infertility (50\%), 9 patients 
presented with pain (45\%) and one patient presented with recurrence after surgery $(5 \%)$.

Inclusion criteria: Patient diagnosed by varicocele unilateral or bilateral by U/S scrotal Doppler and confirmed by venography during the procedure. No age predilection.

Exclusion criteria: Bleeding tendency. Any contraindication to contrast injection: high serum creatinine or allergy.

Ethical consideration: Obtaining an informed consent from the patient concerning the complications of the procedure, the complications of the sclerosant and the acceptance of the involvement in the study. The study was approved by the Ethics Board of Ain Shams University.

Ultrasound imaging: All cases were examinaed by U/S. The examination revealed, 12 cases had bilateral varicocele and 8 cases, had left sided varicocele.

Semen analysis: 10 patients with infertility, 5 patients had low number only, 3 patients had low motility and 2 patients had low number and decreased motility.

\section{Statistical analysis}

Data were coded and entered using the statistical package SPSS (Statistical Package for the Social Sciences) version 23. Data were summarized using mean, standard deviation, median, minimum and maximum in quantitative data and using frequency (count) and relative frequency (percentage) for categorical data. Comparisons between quantitative variables were done using $\mathrm{Chi}^{2}$ and paired $t$ test.

Chi-square test

P-value $>0.05$ Non significant

$\mathrm{P}$-value $<0.05$ Significant

P-value $<0.01$ Highly significant

\section{RESULTS}

The 20 patients enrolled in this study were ranging from 16 to 42 years with mean age of 28.6 years.

Table (1): Representing the statistical data analysis for different ages enrolled at our study.

\begin{tabular}{|l|c|}
\hline \multicolumn{1}{|c|}{ Age (years) } & No. $=\mathbf{2 0}$ \\
\hline Mean \pm SD & $28.60 \pm 7.61$ \\
Range & $16-42$ \\
\hline Age $<30$ & $12(60.0 \%)$ \\
Age $>30$ & $8(40.0 \%)$ \\
\hline
\end{tabular}

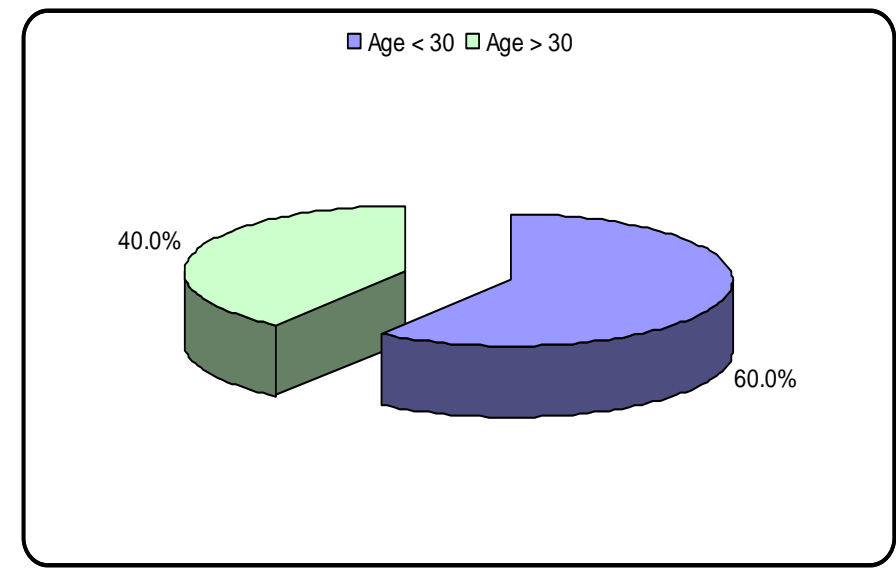

Figure (1): Showing that in our study 12 patients were less than 30 years $(60 \%)$, and 8 patients were older than 30 years $(40 \%)$.

\section{Presenting complaints includeed:}

10 patients presented with infertility (50\%), 12 patients presented with pain $(60 \%)$ and one patient presented with recurrence after surgery $(5 \%)$.

Table (2): Demonstating statistical analysis as regard the clinical indication for varicocele embolization.

\begin{tabular}{|l|l|c|c|}
\hline \multicolumn{2}{|c|}{ Clinical indication } & No. & \% \\
\hline \multirow{2}{*}{ Pain } & No & 8 & $40.0 \%$ \\
& Yes & 12 & $60.0 \%$ \\
\hline \multirow{2}{*}{ Infertility } & No & 10 & $50.0 \%$ \\
& Yes & 10 & $50.0 \%$ \\
\hline \multirow{2}{*}{ Recurrence } & No & 19 & $95.0 \%$ \\
& Yes & 1 & $5.0 \%$ \\
\hline
\end{tabular}

By imaging assessment:

All cases were examinaed by U/S, the examination revealed, 12 cases had bilateral varicocele and 8 cases had left sided varicocele.

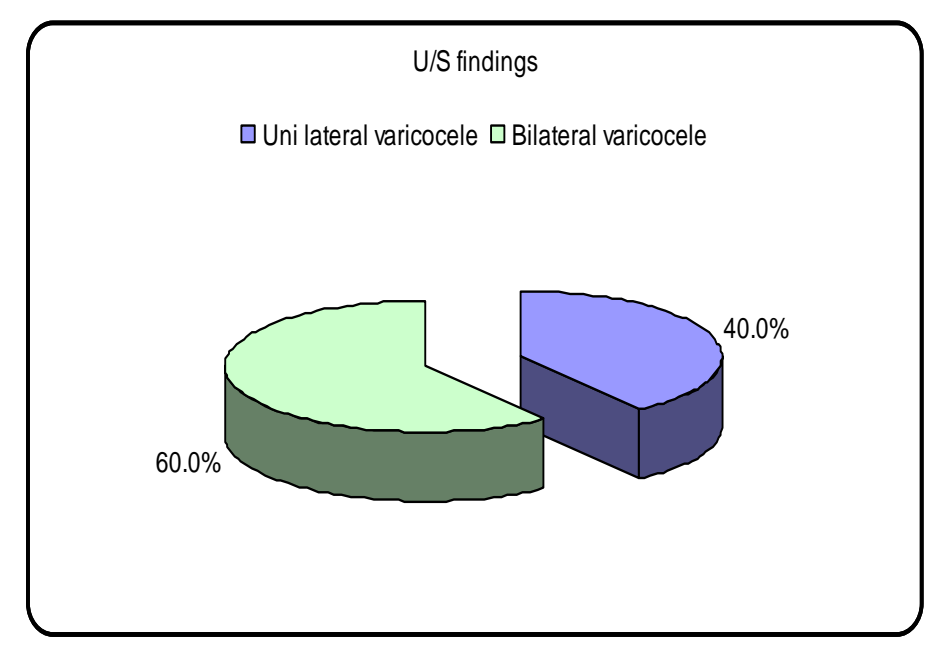

Figure (2): Representing the percentage of patient with unilateral varicocele $(40 \%)$ and bilateral varicocele $(60 \%)$. 
Table (3): Demonstrating the percentage of patients with right and left side varicocele according to the grade.

\begin{tabular}{|c|c|c|c|}
\hline & & No. & $\%$ \\
\hline \multirow{4}{*}{ Right side Grade } & No & 7 & $35.0 \%$ \\
\hline & I & 9 & $45.0 \%$ \\
\hline & II & 3 & $15.0 \%$ \\
\hline & III & 1 & $5.0 \%$ \\
\hline \multirow{3}{*}{ Left side grade } & $\mathrm{I}$ & 3 & $15.0 \%$ \\
\hline & II & 10 & $50.0 \%$ \\
\hline & III & 7 & $35.0 \%$ \\
\hline
\end{tabular}

\section{Semen Analysis}

10 patients with infertility (50\%), 5 patients had low number only, 3 patients had low motility and 2 patients had low number and decreased motility.

Table (4): Demonstrating the statistical data for patients presented with infertility, abnormal number range from (3-11 million/ml), and abnormality in motility range from $5-15 \%$.

\begin{tabular}{|l|l|c|}
\hline \multicolumn{2}{|l|}{} & No.= 20 \\
\hline $\begin{array}{l}\text { Semen analysis } \\
\text { abnormality }\end{array}$ & Normal & $10(50.0 \%)$ \\
\hline Number & Mean \pm SD & $7.00 \pm 2.65$ \\
(million/ml) & Range & $3-11$ \\
\hline \multirow{2}{*}{ Motility \% } & Mean \pm SD & $11.80 \pm 4.15$ \\
& Range & $5-15$ \\
\hline
\end{tabular}

The procedure done for the different categories of the patients in our study, 15 patient underwent left ISV embolization, 3 cases underwent bilateral ISV, in one patient we embolized right ISV, and failed at one case to cathetrize ISV.

Table (5): Demostrating the pocedure approach either jugular or femoral and the side of gonadal vein embolized.

\begin{tabular}{|l|l|c|c|}
\hline \multicolumn{2}{|c|}{} & No. & \% \\
\hline \multirow{3}{*}{ Procedure } & Failed & 1 & $5.0 \%$ \\
& Left & 15 & $75.0 \%$ \\
& Right & 1 & $5.0 \%$ \\
& Bilateral & 3 & $15.0 \%$ \\
\hline \multirow{5}{*}{ Approach } & Femoral & 1 & $5.0 \%$ \\
& Jugular & 18 & $90.0 \%$ \\
& Failed & 1 & $5.0 \%$ \\
\hline
\end{tabular}

Table 5 demonstrating the data for the procedure either embolization of right, left, bilateral ISV and one case failed embolization of left ISV, $90 \%$ of patients were done via jugular approach, $10 \%$ of patients were done via femoral approach.

Table (6): Demonstating the precentage of complications among our patients sample.

\begin{tabular}{|l|l|c|c|}
\hline \multicolumn{2}{|l|}{} & No. & \% \\
\hline \multirow{2}{*}{ Complications } & No & 12 & $60.0 \%$ \\
& Yes & 8 & $40.0 \%$ \\
\hline Pain & 5 & $25.0 \%$ \\
\hline ISV perforation & 2 & $10.0 \%$ \\
\hline Extravasation & 2 & $10.0 \%$ \\
\hline Failed procedure & 1 & $5.0 \%$ \\
\hline
\end{tabular}

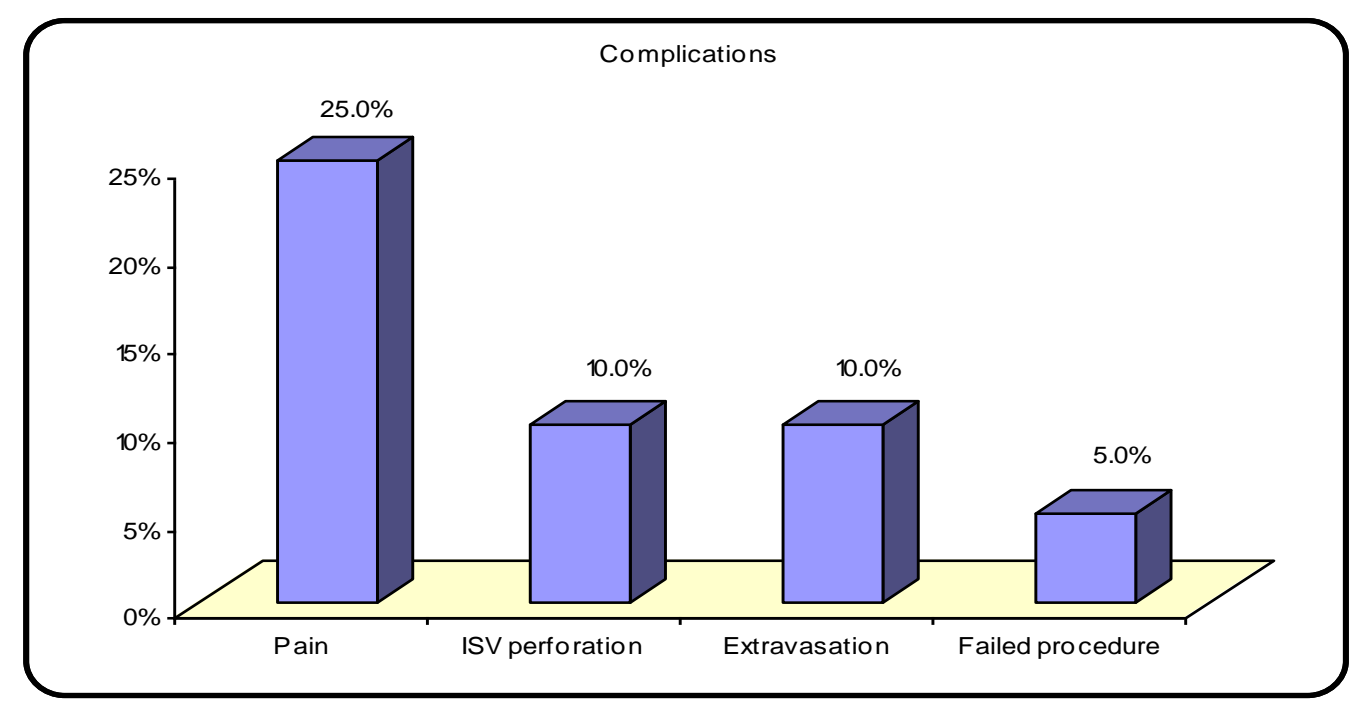

Figure (3): Representing the percentage of complications.

Comparison between pre procedure and post procedure regarding pain. 
Table (7): Comparison between pre procedure and post procedure regarding pain.

\begin{tabular}{|c|c|c|c|c|c|c|c|c|}
\hline & \multicolumn{2}{|c|}{ Pre } & \multicolumn{2}{|c|}{ Post } & \multirow{2}{*}{$\begin{array}{c}\text { Test } \\
\text { value* }^{*}\end{array}$} & \multirow{2}{*}{$\begin{array}{c}\text { P- } \\
\text { value }\end{array}$} & \multirow{2}{*}{ Sig. } \\
\hline & & No. & $\%$ & No. & $\%$ & & & \\
\hline Pain & $\begin{array}{l}\text { No } \\
\text { Yes }\end{array}$ & $\begin{array}{c}8 \\
12\end{array}$ & $\begin{array}{l}40.00 \% \\
60.00 \%\end{array}$ & $\begin{array}{c}15 \\
5\end{array}$ & $\begin{array}{l}75.0 \% \\
25.0 \%\end{array}$ & 5.013 & 0.025 & $\mathrm{~S}$ \\
\hline
\end{tabular}

The previous table shows that there was statistically significant decrease in percentage of pain from $60 \%$ pre procedure to $25 \%$ post procedure with $p$-value $=0.025$.

Table (8): Comparison between pre procedure and post procedure regarding number and motility.

\begin{tabular}{|l|l|c|c|c|c|c|}
\hline \multicolumn{2}{|c|}{} & Pre & Post & $\begin{array}{c}\text { Test } \\
\text { value* }\end{array}$ & $\begin{array}{c}\text { P- } \\
\text { value }\end{array}$ & Sig. \\
\hline $\begin{array}{l}\text { Number } \\
\text { (million/ml) }\end{array}$ & $\begin{array}{l}\text { Mean } \pm \text { SD } \\
\text { Range }\end{array}$ & $\begin{array}{c}7.00 \pm 2.65 \\
3-11\end{array}$ & $\begin{array}{c}28.00 \pm 10.89 \\
15-37\end{array}$ & -3.909 & 0.030 & S \\
\hline Motility \% & Mean \pm SD & $\begin{array}{c}11.80 \pm 4.15 \\
5-15\end{array}$ & $\begin{array}{c}45.80 \pm 6.94 \\
34-50\end{array}$ & -7.641 & 0.002 & HS \\
\hline
\end{tabular}

The previous table shows that there was statistically significant increase in number and motility of the studied cases with p-value $=0.030$ and 0.002 respectively.

Concerning three months follow up, 2 cases not improved as regard the semen analysis, one patient had improvement of the motility but the number was not improved, all patient with pain were improved, 8 out of 10 patients had improved semen analysis results at 3 months follow up.

Two cases with poor outcome, that after 3 months they had low number and motility results of their semen analysis and one case failed to catheterize the ISV.

\section{DISCUSSION}

The methods of varicocele repair continue to evolve as outcomes are variable and variably reported. many favor the percutaneous transcatheter technique as a first-line treatment because it is a minimally invasive outpatient procedure and has minimal complication rates ${ }^{(7)}$.

In our study, we included twenty patients, 10 patients were complaining of infertility, 9 cases complain of pain and one case complain of recurrence after surgery. Ramasamy $^{(8)}$,in his study he said that varicocele embolization is a viable option for treatment of varicocele in patient with scrotal pain and in patient with primary infertility with improvement in seman analysis parameters and pregnancy rates after embolization .

As regard technical sucess, in our study, in one case we failed to cathetrize the diseased left gonadal vein via both jugular and femoral approach with technical success rate $95 \%$. Trombetta et al. ${ }^{(9)}$, concluded that targeted overall reported technical success rate, as cited by the Journal of Vascular and Interventional Radiology quality improvements guidelines, is 83 to $96 \%$, with a clinical or imaging detected recurrence rate at 6 weeks of 7 to $16 \%$. These numbers reflect the range of reported results ${ }^{(9)}$.

In our study, we had 10 patients with infertility $(50 \%), 5$ patients had low number only, 3 patients had low motility and 2 patients had low number and decreased motility,our results showed that there was statistically significant increase in number and motility of the studied cases with $\mathrm{P}$ value $=0.030$ and 0.002 respectively.Gat et al . ${ }^{(10)}$ concluded that clinical outcomes of percutaneous ISV embolization or sclerotherapy are similar to surgical procedures. Semen parameters such as sperm concentration and motility improve in 70 to $82 \%$ of patients, and morphology infrequently improves ${ }^{(\mathbf{1 0})}$.

Also , our preiviously mentioned study results as regard improvment of semen parameters were concurrent with $\mathbf{N a b i}$ et $\boldsymbol{a l} .{ }^{(11)}$, he recorded improvement in semen in terms of motility and morphology in those with retreatment semen density 10-30 million/ml, ${ }^{(11)}$ Gandini et al. another study performed on 244 patients by Gandini et al., yielded improvement in all semen parameters was achieved after treatment. ${ }^{(\mathbf{1 2})}$

All the prieviously mentioned Studies, suppourt the role of percutaneous embolization of varcicoele, in treatment of primary infertility and improvment of semen parameters which was one of the mainn goals of our study .

In our study, there was statistically significant decrease in percentage of pain from $60 \%$ pre procedure to $25 \%$ post procedure with $\mathrm{p}$-value $=$ 
0.025. Puche-Sanz et al. ${ }^{(13)}$ he agreed with our results, as in his study he performed a retrospective review of 154 patients who underwent embolization of varicocele for pain. Using visual analog scale pain questionnaires (range 1-10), median preoperative pain was 7 and postoperative pain was 0 . At 39 months follow-up, $86.9 \%$ of patients had complete resolution of pain. ${ }^{(\mathbf{1 3})}$, thus results from our study and the previously mentioned study indicated that embolization may be an appropriate option for patients with a painful varicocele.

In our study, we have one case of reccurence after surgery that we decided to treat via jugular approach and embolized the left gonadal vein successfuly.Jargiello et $\boldsymbol{a l}^{(\mathbf{1 4 )}}$ answered the question of how we manage recurrent varicocele after surgery as he said : if the varicocele recurs, endovascular treatment is still performed via a retrograde way by accessing the left gonadal vein via the left renal vein, either from a right internal jugular or right femoral vein approach. Jargiello et al. published $100 \%$ technical success in the endovascular treatment of surgically recurrent varicoceles ${ }^{(\mathbf{1 4})}$.

In our study, we included patients from all age group without restrictions, as there is no contraindication to do the procedure in patient with systemic disease, also we did bilateral embolization in 3 cases successfully without complications or any need for hospital stay, Alqahtani et al. ${ }^{(15)}$, agreed with our conclusion as he admit that patients with cardiopulmonary comorbidities can undergo varicocele embolization under local anesthesia, whereas general anesthesia is routinely necessary with surgical repair. additionally, patients with bilateral varicoceles can undergo catheter-based embolization via one single femoral vein access, in contrast to two separate surgical incisions with operative interventions. Without the need to create a surgical incision, catheter-based varicocele embolization is associated with a significant lower risk for wound complications such as infection or dehiscence ${ }^{(15)}$.

Cassidy et al. ${ }^{(16)}$,discussed the technical and clinical success at larger scale, and his results were going with our date as he published a review which represents the largest contemporary series of varicocele embolization outcomes currently available in the literature. The overall technical failure rate for varicocele embolization of $13.9 \%$ is consistent with the published meta-analysis rate of $13.05 \%$. However, the high technical failure rate seen in Cassidy's series in patients with right-sided embolization attempts of $19 \%$ has not been previously addressed in the published literature and is something that can have significant implications for the infertile male seeking to optimize his semen parameters and fertility potential. The overall failure rate of $3.2 \%$ for left-sided embolization attempts is comparable to the $3.25 \%$ published rate of failure for surgical varicocele repair; this result suggests that these two options are equally effective, although embolization offers some advantages in terms of recovery time and safety ${ }^{(\mathbf{1 6})}$.

In our study,as regard post procedural complications : 5 of our twenty patients had hypochondrial pain related to the site of gonadal vein embolization that last from 5 days to week that was controlled with analgesics another two patients had minimal perforation of the gonadal vein during the procedure but the technique was completed successfuly. Reiner et al. ${ }^{(17)}$, concluded that occurrence of post-embolization pain seems to be more frequent when using cyanoacrylate and sclerosing agents rather than coils, and this symptom is related to the secondary phlebitis that they cause. ${ }^{(17)}$.Nabi et al. ${ }^{(11)}$, agreed with our rates of complications as he mentioned that the complications of percutaneous therapy are infrequent and typically mild Complication rates in recent literature have been reported from $0 \%$, to $5 \%$ and $11 \%{ }^{(11)}$.

In our study, we used NBCA: Lipidol mixture in all 20 cases, with one case of recurrence of varicocele detected by ultrasound at 3 months follow up, And there was no chronic complications as regard using NBCA only without adding coils.Vanlangenhove et al. ${ }^{(18)}$, supported the use of NBCA for embolization, as he mentioned thatembolization with NBCA is cost-effective. One cc is comparable in cost to a single conventional pushing coil and is sufficient for successful treatment in the majority of cases. If using controlled-release coils or nitinol plugs, the cost is significantly higher. ${ }^{(\mathbf{1 8})}$

\section{LIMITAIONS OF THE STUDY}

A limitation of this study is that it's small sample size from a single center. It would be beneficial to conduct a comparative study with the standard treatment using coil embolization or surgery.

\section{CONCLUSION}

In our study there was significant improve in patient complain of scrotal pain, and significant improve as regard sperm count $/ \mathrm{ml}$ in comparison to pre and post procedural data, and highly significant improve of motility in 3 months follow up. 
In conclusion, the use of $\mathrm{N} 2 \mathrm{BCA}$ as an embolic agent for percutaneous treatment of varicoceles is a thera-peutic alternative that is effective, safe, simple and inex-pensive. N2BCA triggers a local inflammatory reaction that promotes sclerosis and thrombosis. The liquid nature of the embolization product allows diffusion through the gonadal vein and their collaterals, which appears to reduce recurrence and improve results.

\section{REFERENCES}

1. Alsaikhan B, Alrabeeah K, Delouya G, Zini A (2016): Epidemiology of varicocele. Asian Journal of Andrology, 18(2):179-180.

2. Cina A, Minnetti M, Pirronti T et al. (2006): Sonographic quantitative evaluation of scrotal veins in healthy subjects: normative values and implications for the diagnosis of varicocele. European Urology, 50(2):345-350.

3. Choi WS and Kim SW (2013): Current issues in varicocele management: a review. World J Mens Health, 31(1):12-20.

4. Urbano J, Cabrera M, Alonso-Burgos A (2014): Sclerosis and varicocele embolization with N-butyl cyanoacrylate: experience in 41 patients. Acta Radiol., 55:179-185.

5. Gazzera C, Rampado O, Savio L et al. (2006): Radiological treatment of male varicocele: technical, clinical, seminal, and dosimetric aspects. Radiol Med (Torino), 111:449-58

6. Cooper TG, Noonan E, Von Eckardstein $\mathrm{S}$ et al. (2010): World Health Organization reference values for human semen characteristics. Human reproduction update, 16(3):231-245.

7. Hargreave TB (1993): Varicocele-a clinical enigma. $\mathrm{Br}$ J Urol., 72(4):401-408.

8. Ramasamy R (2014) : Percutaneous embolization: a viable treatment option for varicocele. Basic Clin Androl. ,24:10.
9. Trombetta C, Liguori G, Bucci $S$ et al. (2003): Percutaneous treatment of varicocele. Urol Int., 70(2):113-118.

10.Gat Y, Zukerman Z, Chakraborty J, Gornish M (2005): Varicocele, hypoxia and male infertility. Fluid mechanics analysis of the impaired testicular venous drainage system. Hum Reprod., 20:26142619.

11.Nabi G, Asterlings S, Greene DR, Marsh RL (2004): Percutaneous embolization of varicoceles: outcomes and correlation of semen improvement with pregnancy. Urology, 63(2):359-363.

12. Gandini R, Konda D and Reale CA (2008): Male varicocele: transcatheter foam sclerotherapy with sodium tetradecyl sulfate - outcome in 244 patients. Radiology, 246:612-618.

13.Puche-Sanz I, Flores-Martin JF, Vazquez-Alonso F et al. ( 2014) :Primary treatment of painful varicocoele through percutaneous retrograde embolization with fibred coils. Andrology,2:716-20.

14.Jargiello T, Drelich-Zbroja A, Falkowski A et al. (2015): Endovascular transcatheter embolization of recurrent postsurgical varicocele: anatomic reasons for surgical failure. Acta Radiologica, 56(1):63-9.

15. Alqahtani A, Yezbeck S, Pubois J et al. (2002): Percutaneous embolization of varicocele in children: a canadian experience. J Pediatr Surg., 37:783-785.

16. Cassidy D, Jarvi K, grober E et al. (2012): Varicocele surgery or embolization: Which is better?. Can Urol Assoc J., 6(4):266-8.

17. Reiner E, Jeffrey S, Robert I (2011): Varicocele Embolization In Kandarpa K. and Machan L.(eds): Handbook for interventional radiologic procedures. a lippincott Williams $\&$ wilkins, $4^{\text {th }}$ edition.

18. Vanlangenhove $P$, De Keukelerie $K$, Everaert $K$ (2012): Efficacy and Safety of Two Different nButyl-2-Cyanoacrylates for the Embolization of Varicoceles: A prospective, randomized, blinded study. Cardiovasc Intervent Radiol., 35: 598-606. 